\title{
SUMMING UP
}

\section{(Introduction to the General Discussion)}

\author{
T. L. V. Ulbricht \\ Ph.D., D.Sc., F.R.I.C.* \\ Agricultural Research Council, London
}

IT would be useful to sum up and try to clarify some of the main issues of this Symposium.

It is important to understand that, in science, it is logically impossible ever to prove the truth of a hypothesis or theory. A hypothesis becomes accepted if the experimental evidence is consistent with it and if it appears to explain a number of otherwise apparently unrelated pieces of evidence better than any rival hypothesis. A good hypothesis is one that is amenable to test; if it passes the test, the hypothesis stands and may become accepted as a theory. If it fails, it is discarded.

With the hypothesis that the incidence of coronary heart disease depends significantly on certain factors in the diet, we encounter a special difficulty. The best test that we could devise would be to take 2 large groups of people, put them on different diets, and monitor them for 20 years or more-an experiment impossible to perform on free-living human populations! We have to ask ourselves therefore, what evidence we would regard as convincing in these circumstances.

We were reminded by Dr Turner that there have now been no less than 20 different national and international reports on diet and coronary heart disease. In their conclusions there are some differences in detail, but they are virtually unanimous in recommending a reduction in the dietary intake of total fat, especially saturated fat, of cholesterol and sugar, and increasing the intake of complex carbohydrate and fibre. Experts all round the world have come to these same conclusions. Of course, not all experts absolutely agree about everything,and we have to ask ourselves where the balance of probability lies. Personally I am convinced by this evidence and believe that it provides a sound basis for action.

It is generally accepted that, in addition to diet, a number of other factors affect susceptibility to the disease, including smoking, hypertension, stress, and diabetes. Well then, if diet is merely one of

\footnotetext{
* The views expressed are the personal ones of the author, and not those of his organization.
}

several important factors, are we not giving it too much importance? Dr Ball referred to evidence from Japan which, like the Western countries in which there is a very high incidence of coronary heart disease, is a highly industrialized and urbanized society, with a lot of stress. The men there smoke more cigarettes than in any other country, hypertension is more prevalent there than anywhere else, yet the incidence of coronary heart disease is very low, even amongst diabetics. But the incidence in Japanese who have emigrated to Hawaii or the United States and adopted local dietary practices is the same as in the local population. This suggests very strongly that, although it is a multifactoral disease, diet is the fundamental cause.

If the government took measures, by adjusting prices for example, to influence what people eat, would this not be an interference with our freedom of choice? We must appreciate that what we eat is already influenced by many things, certainly by advertising and by prices. Currently we have a butter subsidy for example, and undoubtedly this influences consumption. The price structures set by the EEC Common Agricultural Policy or by our Government in its support of the agricultural industry effects the price of food in the shops and therefore, in part, determines what we eat now. The only difference is that, at present, nutritional considerations affecting the long-term health of the population are completely ignored when price structures are set.

In fact, we would like more freedom of choice. We would like low-fat milk to be generally available, as it never is in most civilized countries, and low-fat cheese. We would like, also, to be given the opportunity of genuinely exercising choice, which is almost impossible now because of the wholly inadequate labelling of food products.

If the changes in diet which are being recommended were widely adopted, would it not be very difficult for the food and agricultural industries to adapt? Of course they could not adapt overnightbut then, the most optimistic amongst us envisage 
that the changes we recommend would take very many years to implement. The kind of changes we are discussing seem to be relatively minor compared to other changes that have occurred in industry. In Sweden, the food industry has cooperated very actively with the Government, not only in changing products but also in advertising, to encourage dietary change. This campaign has been successful in the upper income groups in reducing sugar consumption and in arresting, and then reversing, the long-term decline in bread consumption. They have not yet succeeded in reducing fat consumption, but a start has been made and what I think is most encouraging is the way that the Swedish food industry has participated in it.

Agriculture will also need to adapt, but I foresee no problems. Agriculture is changing and adapting all the time, and responds remarkably quickly to technical innovation and to market demand. If the demand for meat, especially fatty meat, declines, and less grain is required for fattening animals for the market, the land that grew feed barley may be used to grow more oil-seed crops such as rape-seed. Some of the land may be used to grow hard-milling wheat; I hope you all know that to make real bread-bread from wholewheat flour-it is not necessary to use any imported hard wheat at all.

Can we really change our national diet? We can begin by changing our own, and by setting an example. In my family we have changed our diet in this way, quite painlessly, in fact with great pleasure, because we all enjoy our food. The children accept the diet and of course, if they are invited out, they may eat whatever they like. It is interesting that they have become critical and discriminating as a result. But what is your attitude when you go out, and when you travel? Do you eat bacon and egg because it's included in the price of bed and breakfast? When the Nutrition Society or some other worthy body holds a meeting and serve you with white bread, do you complain? If we don't set an example, and sometimes complain, can we blame others that things are changing so slowly?

A meeting such as this cannot propose specific lines of action. However, it was impressive to hear from Professor Joossens that the change in diet in Belgium, beginning in the Flemish-speaking region, had been initiated by the nutrition teaching of students in the Medical Schools. Perhaps the greatest help a benefactor could give would be to endow a new chair of nutrition in one of our leading Medical Schools-a chair of 'Nutrition in relation to Preventive Medicine'. We have heard again at this conference of the neglect of this subject and in particular, that students of medicine are almost not taught it at all. One new centre of excellence for teaching and research in nutrition could make as tremendous difference. Through a better educatede medical profession we could reach pregnant mothers and mothers of young children, the most important members of the population as far as the future is concerned. 